\title{
The Clinical Learning Experiences of Nursing Students Caring for Elderly Schizophrenia Inpatients
}

\author{
Chia-Shan $\mathrm{Wu}^{1,2}$, Jiin-Ru Rong ${ }^{2}$, Wen-Kuei Liao ${ }^{2,3}$, Hsun-Wen Chang ${ }^{1} \&$ Wei-Na Hsu ${ }^{1}$ \\ ${ }^{1}$ Department of Nursing, National Tainan Junior College of Nursing, Tainan, Taiwan \\ ${ }^{2}$ Department of Nursing, National Taipei University of Nursing and Health Sciences, Taipei, Taiwan \\ ${ }^{3}$ Department of Nursing, St. Mary's Junior College of Medicine, Nursing and Management, Yilan, Taiwan \\ Correspondence: Prof. Jiin-Ru Rong, Department of Nursing, National Taipei University of Nursing and Health \\ Sciences, No.365, Ming-te Road, Poitou District, Taipei City, Taiwan. Tel: 886-2-2822-7101.
}

Received: September 17, 2019

doi:10.20849/ijsn.v4i4.660
Accepted: October 8, $2019 \quad$ Online Published: October 12, 2019

URL: https://doi.org/10.20849/ijsn.v4i4.660

\begin{abstract}
Aims: Young nursing students who are engaged in psychiatric nursing practice for the first time have many difficulties. In order to help students learn how to care for elderly patients with mental illness, this study explored student perceptions, evaluated clinical learning experiences using qualitative research methods, and assessed the experiences of student nurses in caring for elderly patients with schizophrenia in Taiwan.

Methods: The data presented in this study were derived from an qualitative study based on a phenomenological approach. The 20 participants were selected from the students of a nursing college in Taiwan. Individual in-depth interviews were held with nursing students, these students were selected from the fourth-years of nursing college of associate degree. The mean age of all of the participants were 18.7( \pm 0.46$)$.

Results: Colaizzi's analysis method was used to analyze the data. Six main themes were obtained: (1) Assessing clinical problems associated with psychiatric disorders and geriatric diseases; (2) Preparing for and engaging with the clinical internship environment; (3) Establishing relationships with elderly patients; (4) Participating in clinical learning and applying nursing knowledge and skills; (5) Shaping a good attitude towards elderly schizophrenia patients; (6) Gaining confidence in the internship process.

Conclusions: Although nursing students lack clinical knowledge and situational experience in geriatric psychiatric nursing, nursing teachers need to help students be more perceptive and evaluate their clinical learning experiences, and to express themselves and reflect on the process of care delivery to hospitalized elderly patients with schizophrenia.
\end{abstract}

Keywords: geropsychiatric nursing, schizophrenia, nursing student, clinical nursing internship

\section{Introduction}

Faced with rapid aging, people with schizophrenia encounter multiple problems, including mental disease and problems associated with aging. In Taiwan, the average age of people with schizophrenia has increased to 54 years old, and the rate of their aging is $20 \%$ higher than that of the general public (Hsu, 2012; Hsieh, Su, Liu, Kao \& Hung, 2015). Elderly patients with mental disorders, depression, or dementia who also have chronic health problems require more comprehensive nursing. Nurses in Taiwan and the nursing profession in general are concerned with geropsychiatric nursing competency, and emphasize the need for clinical training to prepare for care delivery to elderly psychiatric patients (Batchelor-Aselage, et al., 2014; Rong, Wu, \& Liao, 2018). However, nurses are not ready to take care of the mental health needs of the growing elderly population. Nursing schools should incorporate courses dealing with psychiatric and mental health nursing for the elderly into the curriculum, after which students can apply the knowledge to real situations and learn appropriate clinical practice (Karimollahi, 2012; Kuven \& Giske, 2019).

The aim of clinical practice courses in psychiatric and mental health nursing programs is to provide nursing students with the opportunity to integrate their knowledge and skills with their attitudes towards psychiatric patients(Choi, Hwang, Kim, Ko, Kim \& Kim, 2016; Kuven \& Giske, 2019). The teaching and practice of psychiatric and mental health nursing can improve nursing students' attitudes towards psychiatric patients. 
Through clinical practicum experiences, nursing students gain a better understanding of mental disorders and the health care needs and problems of psychiatric patients (Ketola and Stein, 2013; Karimollahi, 2012; Lin \& Li, 1995).

The School of Nursing does not have a systematic plan for educating students in geriatric psychiatric nursing and internships, which may affect the practical ability of nursing students or nurse caregivers to care for elderly schizophrenia patients. There are not enough teaching and internship resources available in Taiwan for training mental health nurses to care for the elderly (Rong, Wu, \& Liao, 2018; Kuven \& Giske, 2019). On the other hand, young nurses or nursing students may also have stereotyped and negative attitudes towards elderly patients with mental problems or disorders, thus affecting their caring interactions and nursing ability (Rong, Wu, \& Liao, 2018).

Development of clinical, home, and residential care capabilities for the elderly and improvement of the overall care quality for the elderly are important issues, worthy of attention by nursing education and the clinical professionals. However, many clinical difficulties are worth reviewing to improve mental health care practice for the elderly and the teaching of geriatric mental health care or continuing education and training. Nursing students have limited interactive experiences with the elderly in daily life. Clinical teaching focuses on the care of the elderly with acute-phase disease, which facilitates the creation of barriers between generations in language, culture, and values, resulting in generation gaps or generational stereotypes that impact the quality of elderly care (Rong, Lin, Liu, \& Hsu, 2013; 2014). Nursing courses mainly deal with the assessment, diagnosis, and treatment of physical diseases, and pay little attention to geriatric mental health problems. As a result, nursing students are not sufficiently prepared to detect the mental health problems of the elderly, lack the ability to make the appropriate assessment and provide appropriate nursing treatment, and lack the ability to understand the feelings of the elderly and their families concerning their care. Thus, these deficiencies will affect the early detection of senile mental diseases and the provision of appropriate medical treatment and care (McCabe, Davison, Mellor, \& George, 2008). At the present stage, clinical nursing courses are mostly designed by teachers. Teachers monitor closely students' clinical learning experiences to prevent or manage clinical learning problems. Although a student-centered approach to clinical nursing teaching is advocated, traditional education is actually teacher-centered and affects the ability of nursing students to actively learn, reflect and critically think about their professional, which results in their lack of skill in their nursing professional after graduation, not to mention ability to learn and provide quality geriatric physical and mental health care.

In view of the above, nursing educators need to actively examine and innovatively plan the geropsychiatric nursing education module, design curriculum and teaching strategies, and implement and evaluate an outcome-based learning approach.

Nursing professionals emphasize that nursing skills should incorporate nursing knowledge into clinical practice. In addition, the clinical practice of nursing plays an important role in nursing student and nursing staff development, integrating nursing knowledge, and establishing nursing attitudes toward patients and clinical skills in specific fields. In order to cope with the diverse, changeable, and complex health care needs and problems of individuals, clinical nursing education should not be limited to applying classroom knowledge to practical situations. Clinical education models are needed to foster independent learning in nursing students and staff, improve bedside care, problem-solving, critical thinking skills, synthesize practical with professional knowledge, and choose the right nursing interventions ( $\mathrm{Li}, \&$ Chung, 2012). The main purpose of this study is to explore (1) the practical experiences of students in psychiatric wards caring for patients with schizophrenia; (2) the resources contributing to learning while engaged in internship activities; (3) the attitudes of students toward caring for elderly schizophrenia patients.

\section{Method}

\subsection{Research Design}

Descriptive phenomenology was used to obtain information about nursing students' learning experience. Phenomenological research provides a useful lens for researchers to explore, describe, and analyze the significance of individual life experience (Chiang \& Yang, 2018; Mason, 2018; Rafati, Nouhi, Sabzehvari \& Dehghan-Nayyeri, 2017; Van Manen, 2016). The complete subjective learning experiences of research subjects in this study were elicited by semi-structured, in-depth descriptive personal interviews on specific issues. Students were asked to answer the following questions relating to the activities of caring for elderly schizophrenia patients: (1) How do you determine the patient's care needs and problems; (2) What kind of care activities can you provide; (3) How do you use care and learning resources to help you deliver care; (4) What are your views on the elderly schizophrenia patient? These exchanges of ideas are helpful to improving clinical 
teaching and obtaining new learning insights.

\subsection{Data Collection}

The first author conducted in-depth interviews with all participants from February to August 2018 and collected the data. Before each interview, the author interacted with participants for a prolonged period of time, thus winning their trust and obtaining their consent. Purposive sampling was adopted. The following selection criteria were used: (1) completion of the classroom course in mental health nursing, (2) current enrollment in or completion of a nursing practice course in caring for patients with schizophrenia aged 50 or above, (3) willingness to participate in this study. This study recruited 20 participants. This was the first mental health practice placement for our nursing student participants, and the students' practice time was 160 hours and completed within 4 weeks. A fixed clinical practice instructor tutored 8 nursing students, and each student individually cared for elderly schizophrenia patients in a one-on-one manner. The nursing setting was an acute care ward (40 beds) and a rehabilitation ward (50 beds) of a psychiatric specialized teaching hospital. The interview was held in the conference or consultation room of the student clinical practice ward. The space was private and undisturbed. According to the richness of the interview content, each participant was interviewed for 40-60 minutes each time. Each participant was interviewed during the practice and at the end of the practice. After the interview, the content was transcribed word for word immediately. When participants in the learning experience began to show no repetition of new topics, data collection was considered sufficient and was stopped.

\subsection{Data Analysis}

Wirihana et al. (2018) suggested that Colaizzi's phenomenological methodology can be used reliably to understand people's experiences. Each recorded result of the interview was transcribed verbatim. The analysis method devised by Colaizzi (1978) was used in this study to understand nursing students' learning experience. The data of this study were analyzed by two researchers individually, and the meaning of each subtheme and themes was compared between the two researchers. The first step of Colaizzi's method was reading and re-reading of the nursing students' experiences of caring for elderly patients with schizophrenia. Then, each researcher identified all statements directly related to the phenomenon in each verbatim draft and clarified the meaning of the most important statement. Moreover, by systematically grouping statements with similar meanings into categories, theme clusters, and themes. Integrating the collated results, we were able to write a broad description of the research findings. In the final step, the researchers continuously systematically condensed detailed statements into short, important keyword sentences and returning to the participants' statements in the verbatim draft, checked the researcher's interpretation against the original intended meaning of the participants before furnishing final confirmation.

\subsection{Trustworthiness}

Lincoln and Guba's criteria for improving the rigor of qualitative studies including credibility, dependability, confirmability, and transferability have been respected in this study. The whole interview was voice recorded, and the researcher would also take notes on attitude and atmosphere during the interview, thus enabling the participants to freely express their subjective views. After confirming that the participants had expressed their intended meaning, advising professors and peers discussed the results to identify blind spots or errors in the analysis. In terms of dependability, data were collected by a single researcher. The data analysis was repeated and the appropriateness of the analysis was repeatedly reviewed. For confirmability, during processing of data provided by the participants, the researchers used reflection logs for self-reflection continuously to achieve an objective and neutral stand by eliminating bias through adjustment. All chosen participants met the requirements needed for the results to be representative and transferable; were enrolled in this study for the same period of time, were aged 18 to 19 years (Table 1); were able to share their real-life experiences, and, when requested, provided clarification at any time point during the study to ensure the completeness of the contextual data.

\subsection{Ethical Considerations}

The Research Ethics Committee of a hospital in Taiwan provided ethical approval (No. YLH-IRB-10616). Before the interview, the researcher obtained signed consent forms from the interviewees. The data included in the analysis was solely from participants who agreed to be interviewed. Participants could withdraw from the study at any time. The interviewee's thoughts and behaviors were not criticized in any way and did not affect analysis of the results. 
Table 1. Participants characteristics ( $\mathrm{N}=20)$

\begin{tabular}{lll}
\hline Participant & Gender & Age \\
\hline S1 & Female & 19 \\
S2 & Female & 19 \\
S3 & Female & 18 \\
S4 & Female & 19 \\
S5 & Female & 19 \\
S6 & Female & 18 \\
S7 & Male & 18 \\
S8 & Female & 19 \\
S9 & Female & 19 \\
S10 & Female & 19 \\
S11 & Male & 19 \\
S12 & Female & 18 \\
S13 & Female & 19 \\
S14 & Female & 18 \\
S15 & Female & 19 \\
S16 & Female & 19 \\
S17 & Female & 19 \\
S18 & Female & 18 \\
S19 & Female & 19 \\
S20 & Male & 19 \\
\hline & &
\end{tabular}

\section{Results}

Six themes emerged from the analysis of the learning experiences of nursing students caring for elderly patients with schizophrenia: (1) Assessing clinical problems associated with psychiatric disorders and geriatric diseases; (2) Preparing for and engaging with the clinical internship environment; (3) Establishing relationships with elderly patients; (4) Participating in clinical learning and applying nursing knowledge and skills; (5) Shaping a good attitude towards elderly schizophrenia patients; (6) Gaining confidence in the internship process(Table 2). Each theme is described and explained in the following sections.

\subsection{Theme 1: Assessing Clinical Problems Associated With Psychiatric Disorders and Geriatric Diseases}

This means that students began to use observation and personal experience to address problems brought about by mental disease and senility, and assessed the physiological problems and daily life functions of the elderly through assessing their psychiatric symptoms and behavioral problems.

\subsubsection{Assessment of Patients' Psychiatric Symptoms and Behavioral Problems}

This means that nursing students assessed the psychiatric symptoms and behavioral problems of elderly psychiatric patients through observation and therapeutic interaction. Most students focused on the problems of positive and negative psychiatric symptoms, risk of violence, and patient's lack of insight into his or her own illness.

"I found that the patient had persecutory delusion. He often said that he was framed because the television reported that he had killed someone, and he was angry." "It is not easy to assess his thoughts because he had no insight into his psychiatric symptoms." (S5)

"I watched him get excited when he spoke, and he was angry about the TV reporting that he was a murderer. In this situation, I was worried that he would attack the medical staff or other patients. I assessed this patient's risk 
of committing violence against others." (S5)

Table 2. Themes of nursing students' learning experiences

\begin{tabular}{|c|c|}
\hline Theme & Subthemes \\
\hline \multirow{2}{*}{$\begin{array}{l}3.1 \quad \text { Assessing clinical problems } \\
\text { associated with psychiatric disorders } \\
\text { and geriatric diseases }\end{array}$} & $\begin{array}{l}\text { 3.1.1 Assessment of patients' psychiatric symptoms and } \\
\text { behavioral problems }\end{array}$ \\
\hline & 3.1.2 Assessing patients' physiological and self-care problems \\
\hline \multirow{3}{*}{$\begin{array}{l}\text { 3.2 Preparing for and engaging with } \\
\text { the clinical internship environment }\end{array}$} & 3.2.1 Anxiety about clinical practice \\
\hline & 3.2.2 Preparation for student internship \\
\hline & 3.2.3 Connecting the supporting clinical practicum resources \\
\hline \multirow{3}{*}{$\begin{array}{l}\text { 3.3 Establishing relationships with } \\
\text { elderly patients }\end{array}$} & 3.3.1 Learning to quickly establish relationships with patients \\
\hline & $\begin{array}{l}\text { 3.3.2 Keeping Company with patient is a Very Important Way } \\
\text { to Establish a Therapeutic Relationship }\end{array}$ \\
\hline & $\begin{array}{l}\text { 3.3.3 Trying to use language and vocabulary that facilitate } \\
\text { communication and interaction with the elderly }\end{array}$ \\
\hline \multirow{4}{*}{$\begin{array}{l}\text { 3.4 Participating in clinical learning } \\
\text { and applying nursing knowledge and } \\
\text { skills }\end{array}$} & $\begin{array}{l}\text { 3.4.1 Acquiring clinical care skills to help patients deal with } \\
\text { daily life problems }\end{array}$ \\
\hline & $\begin{array}{l}\text { 3.4.2 Acquiring clinical care skills to assist patient symptom } \\
\text { management }\end{array}$ \\
\hline & 3.4.3 Dispensing psychiatric medications \\
\hline & $\begin{array}{l}\text { 3.4.4 Reflecting on and thinking about the significance of } \\
\text { clinical learning to improve psychiatric nursing skills }\end{array}$ \\
\hline \multirow{2}{*}{$\begin{array}{l}\text { 3.5 Shaping a good attitude towards } \\
\text { elderly schizophrenia patients }\end{array}$} & 3.5.1 Reducing the stigma of schizophrenia and aging \\
\hline & $\begin{array}{l}\text { 3.5.2 Rethinking and challenging stereotypes of elderly } \\
\text { schizophrenia patients }\end{array}$ \\
\hline \multirow[t]{2}{*}{$\begin{array}{l}3.6 \text { Gaining confidence in the } \\
\text { internship process }\end{array}$} & $\begin{array}{l}\text { 3.6.1 Achieving a positive self-evaluation of clinical learning } \\
\text { ability }\end{array}$ \\
\hline & 3.6.2 Improving teamwork ability \\
\hline
\end{tabular}

\subsubsection{Assessing Patients' Physiological and Self-Care Problems}

This means that students paid more attention to, and evaluated the physiological problems and daily life functions of elderly patients, including skin condition or injury, pain, digestion, excretion, aspiration of food into the trachea, sleep problems, and self-care functions.

"When I approached the patient who had not bathed for 3 or 4 days, I assessed the patient's self-care ability. Most of elderly schizophrenia patients have comorbid metabolic syndrome. Therefore, I assessed the condition of the patient's physiology, such as skin, digestion, and excretion conditions. In addition, I would pay attention, when the patient went into the bathroom, to whether he actually only took a shower rather than a bath, and then put on the same clothes and did not clean himself at all. I would assess the patient's problems with self-care." (S8).

"I found that elderly patients were prone to choking cough, and the teacher would remind us that we needed to pay attention to choking cough when the elderly patients are eating" (S6)

\subsection{Theme 2: Preparing for and Engaging With the Clinical Internship Environment}

This means that students identified the available internship support resources, and to reduce the tension and anxiety associated with internship, prepared themselves by gradual orientation to the internship environment. 


\subsubsection{Anxiety About Clinical Practice}

This means that students were anxious because of the patient's severe psychotic symptoms such as delusions, paranoia, silence, and self-absorption and lack of communication with the student.

"I cared for an elderly patient with extremely obvious psychiatric symptoms. He couldn't answer my questions at all. He said that he had 70 trillion dollars, and that he could see ghosts and gods. I had no prior experience with caring for psychiatric patients, so I was shocked to see the patient's condition. I wanted to know what caused him to be like this. His psychiatric symptoms were so serious. How could I get along with him? I didn't know what to do in this situation? I wasn't sleeping well and felt exhausted all the time" (S18)

\subsubsection{Preparation for Student Internship}

This means that the following information was provided to the student before the internship: the patient's condition and routine of care. In addition, the patient was informed that the student would be coming to care for him or her, and the clinical teacher would be giving the student guidance. The clinical preceptor would introduce student to the patient and provide a demonstration of effective communication.

"On the first day, the teacher told us which patients were more suitable for us. The clinical teacher and preceptor helped us review the relevant psychiatric nursing information and clinical routine. Moreover, the clinical preceptor helped me approach the patient and introduced me to the patient. Moreover, the clinical teacher or preceptor demonstrated the nursing skills required to work autonomously."(S2)

\subsubsection{Connecting the Supporting Clinical Practicum Resources}

This means that students needed to use learning resources including clinical teachers and preceptors to support their internship. They needed to ask teachers to help them deal with clinical nursing situations and clinical questions through discussion and demonstration. These were the clinical resources that students used during their internship.

"I would work with clinical preceptors and other professionals to provide nursing care to my patients. In the morning meeting, the clinical teacher or preceptor would ask questions about the patients care. At first, I just worried and feared I might not be able to answer these questions. But later, I found that I could work with them. The teacher would also demonstrate how to talk and communicate with the patients and then the preceptors would take us along when dispensing medication, giving me the opportunity to practice and apply skills."(S3)

\subsection{Theme 3: Establishing Relationships With Elderly Patients}

This means that students learned to communicate and build relationships with elderly psychiatric patients as soon as possible during the internship. Students would interact with patients using vocabulary that elderly patients could understand, and also would realize that keeping company with patients is an important way to establish therapeutic relationships.

\subsubsection{Learning to Quickly Establish Relationships With Patients}

This means that students focused on learning how to communicate with elderly patients. Because the internship lasts only one month, students would try to find topics that engaged the patients, would seek opportunities to interact with patients, find channels to build relationships with patients, melt barriers to communication, and establish relationships quickly.

"My patient had dissociative speech. He couldn't respond appropriately to other people's inquiries. When I asked him a question, I might have to repeat it 10 times before he gave a short answer that was sometimes not correct." (S15)

"He almost always lay in bed. He occasionally came out to see the time and then went back to lie down. When I asked him questions, he rarely answered. He would not ask questions or talk about anything. It was not easy to continue talking to him. I could only continue to keep him company and try to find a topic that would encourage conversation. In addition, I needed to understand and assess my patient's conditions. Therefore, I needed to establish a relationship with my patient as soon as possible during the first week or the second week of my internship. (S11)

\subsubsection{Keeping Company With Patient is a Very Important Way to Establish a Therapeutic Relationship}

This means that students realized that companionship was an important way to establish therapeutic relationships, and that they learned how to establish meaningful therapeutic interactions.

"My patient completely ignored me when I first approached him. I approached him and kept him company many times thereafter, but he continued to murmur to himself and walk with his head low, not looking at me. Later I 
realized this was not good for our relationship. I not only kept him company, but also let him know I cared about him. Finally, in the third week of internship, he talked to me, and asked me whether I had eaten lunch. I found that this kind of patient contact was meaningful therapeutic interaction" (S20)

\subsubsection{Using Vocabulary That is Understandable to Elderly Patients}

Students expected to establish therapeutic communication with elderly psychiatric patients, but they were troubled by the patient's short answers or disregard. Students also mentioned that communication with elderly patients was often affected by their inability to use language understandable to elderly people. The intergenerational differences in culture and language forced these young students to learn the vocabulary needed for communication with the elderly.

"My patient only spoke Taiwanese, but I only spoke Mandarin. I was afraid of communicating with elderly patients who might speak Taiwanese. If they spoke too fast, I would not be able to understand them. Sometimes I had to listen to him more than once. After he explained it, I still couldn't understand it. Sometimes I would reply in Mandarin when he finished speaking Taiwanese" (S2)

"My patient was older, sometimes I didn't know what to talk about with him, and I felt that we didn't have a mutual topic of interest. When he talked about his idol Andy Lau, I didn't actually know who Andy Lau was." (S7)

\subsection{Theme 4: Participation in Clinical Learning and Application of Nursing Knowledge and Skills}

It means that students acquired clinical care skills to help elderly patients deal with daily life problems and manage their psychiatric symptoms and behavioral problems through opportunities provided by the internship program.

\subsubsection{Acquiring Clinical Care Skills to Help Patients Deal With Daily Life Problems}

It means that the internship program helped students acquire skills needed for dealing with the daily life problems of elderly patients, and carrying out assessment of nursing support to deal with daily life problems, such as body cleaning, eating, and other problems.

"My patient had very poor self-care practices and often wore the same clothes. I don't think he shaved. I asked him if he wanted to shave, and he told me he would shave tomorrow. So, I learned to take care of this elderly psychiatric patient and also of aspects of his daily life, such as bathing and shaving. He needed to be urged to do it, and I made sure to check it" (S1)

"My patient had gastroesophageal reflux problems, and because he had just stopped taking his stomach medicine, he often complained of discomfort. Every day after breakfast or lunch, I would ask him if he was uncomfortable." (S4)

\subsubsection{Acquire Clinical Care Skills to Assist Psychiatric Symptom Management}

It means that the internship process helped students acquire skills to manage psychiatric symptoms and behavioral problems of elderly schizophrenia patients, including treating their positive and negative symptoms and disorientation disorder, and soothing their emotions.

"My patient had a cognitive disorder. He would wander into other people's rooms, then mess up his own stuff and take other people's stuff. My preceptors had pasted their names on the wall, but it seemed useless. Then I would often need to go to find his stuff and then take him back and say, look, this is your bed number 128. I found that I could not always tell the patient that 'this is not your place and yours is over there', and had to take him directly, otherwise he would not know. He would accept being taken directly, but he could not be told directly, or he would lose his temper. We should use direct methods to help patients modify their symptoms or behavioral problems."(S3)

"My patient's speech was dissociative, he was unable to stay on topic, or provide relevant or correct answers from beginning to end. When I wanted to ask him a question, I needed to ask it 10 times, and only then received a short, not necessarily correct answer. He would keep asking the same question, and when I thought our conversation had ended, he would immediately run back to ask me the same question. And I also needed to learn to soothe patients' chaotic emotions. "(S10)

\subsubsection{Dispensing Psychiatric Medications}

Students could learn nursing skills by finding solutions to the complex problems of elderly patients with schizophrenia or other mental disorders and through participation in their clinical care. For example, while engaged in the task of medication administration, students would experience: helping the patient take the 
medication, determining whether the patient hid the medication or not, evaluating the effectiveness and side effects of the medication, etc.

"I administered the medication every day and also provided medication education to the patient. Every morning, we would tell the patient the purpose of the medication. I would also check to see if he had hidden any medication; and I asked him whether he had any side effects such as excessive saliva secretion, and my patient would say no." (S12)

"I told my patient every day about the effect of the drugs. By the next day he had forgotten. So, I made a drug card, and to help with drug administration, we told him to look at the card every day and learn to look for a drug response and any side effects." (S13)

3.4.4 Reflecting on the Significance of Clinical Learning to Improve Psychiatric Nursing Skills

This means that students reflected on the many real clinical situations in psychiatric nursing that could provide an opportunity to learn and practice treatment-related skills used in the care of elderly schizophrenia patients, and so improve these skills.

"I came here to learn a lot of things that are more practical than what is mentioned in the book. Only from clinical practice can I know how to take care of elderly schizophrenia patients. I received the opportunity to use the skills I learned to care for elderly schizophrenia patients, and gained greater flexibility. For example, communication skills cannot be obtained from the standard answers stated in books. When I came to the clinic, I would learn to respond flexibly in different situations." (S19)

\subsection{Theme 5: Adopting a Good Attitude Towards Elderly Schizophrenia Patients}

This means that students had to change their perceptions of elderly patients with schizophrenia after exposure to elderly patients during their internship. Nursing students mentioned their interactions with the elderly during internship, and how internships changed their perspective on schizophrenia and the elderly.

\subsubsection{Reducing the Stigma Associated With Schizophrenia and Aging}

It refers to the fact that students' perceptions of elderly patients with schizophrenia changed, especially regarding aging and mental diseases, after caring for elderly schizophrenia inpatients.

"I cared for an elderly patient. In the beginning, I think this elderly patient did not know how to communicate with the outside world, and he was very indifferent to me. I was also worried that this elderly schizophrenia patient might attack me. However, during the internship, I realized that these elderly patients were not terrible, and not every patient was aggressive. I had to patiently keep the patient company. After an internship, we could communicate with patients and found them to be very friendly." (S14)

\subsubsection{Rethinking and Challenging the Stereotypes of Elderly Schizophrenia Patients}

This means that contact with and caring for elderly schizophrenia patients caused nursing students to reflect on and challenge their stereotypic assumptions about elderly schizophrenia patients.

"When I started taking care of them, the elderly patients were very quiet, serious and did not smile. However, during the internship, I found that they did not smile because of negative psychiatric symptoms and were not simply ignoring people. When I studied them more and had more contact, they were more willing to respond to me. They would also greet us and be very polite. We really should change our stereotyped views of them." (S9)

\subsection{Theme 6: Gaining Confidence in the Internship Process}

This means that students affirmed the importance of this internship program, during which relationships with the elderly patients developed and confidence in care delivery skills was increased. At the beginning of the internship, students were afraid to interact with patients, but later they developed a willingness to provide care and treatment and satisfy patient needs. Students also mentioned that they could work in teams with other professionals and recognized their abilities, which was apparent from the feedback of clinical teachers and preceptors.

\subsubsection{Positive Evaluation of Self-Clinical Learning}

Students provided a positive self-evaluation of their performance and suggested changes in their internship. During the internship, self-observation and patient interactions improved, and their confidence in nursing of patients increased. Evaluation of their clinical learning was based on feedback.

"I was a little scared when I came to the psychiatric ward, because I didn't know if the patient would accept me? On the first day of the internship, the patient did not speak. I felt that I was very incompetent and I didn't know 
how to care for the patient. After this month-long internship ended, I was not so nervous and was confident I could care for these patients. When the patient asked me questions, I knew how to deal with these problems. The patients would also praise me! I am very happy to be praised! "(S16)

\subsubsection{Better Teamwork Ability}

This means that students could work with other nursing ward staff and professionals during the internship. They were also praised by the medical team staff and internship preceptors, and believed that they could work with the professional team to provide patient care.

"There were many opportunities to cooperate with the psychiatric ward medical team, such as co-interviewing patients, discussing patient status and care activities, and learning from the professional team to care for patients. I was very reticent when I started practicing, and I did not dare to express myself. After this month's practice, I could speak to the medical team and engage them in discussion. The preceptors praised me for my progress and I felt that I could really help patients and work with the professional team." (S17)

\section{Discussion}

Students enhanced their understanding of mental illness through interaction with psychiatric inpatients(Ketola \& Stein, 2013). This present study found that the internship can help nursing students address the issues of care delivery to elderly inpatients with schizophrenia, and the focus of learning was on: (1) Assessing clinical problems associated with psychiatric disorders and geriatric diseases; (2) Preparing for and engaging with the clinical internship environment; (3) Establishing relationships with elderly patients; (4) Participating in clinical learning and applying nursing knowledge and skills; (5) Shaping a good attitude towards elderly schizophrenia patients; (6) Gaining confidence in the internship process.

Compared to the general population, patients with schizophrenia suffer in a higher proportion from physiological chronic diseases. The medical care they need is more complex than the general population with chronic diseases. The age, disease, and side effects of antipsychotics in elderly patients with schizophrenia affect the health problems of patients and the decline in activities of daily living(Hsu, 2012; Hsieh et al., 2015). Other studies reported that positive psychotic symptoms of the elderly with schizophrenia, though gradually stabilized, aggravate negative psychotic symptoms, cognitive ability decline, emotional apathy and depression, and multiple problems associated with the need for interaction with the outside world(Cheng, Yip, Jim, \& Hui, 2012; Hsieh et al., 2015; Jeste \& Maglione,2013). Nursing students should be able to assess the psychiatric symptoms, behavioral problems, physiological health problems, self-care ability changes, and health care needs of elderly with schizophrenia in clinical situations(Beck, Buckwalter, \& Evans, 2012; Rong, Wu, \& Liao, 2018). The results of this study showed that students need to learn how to assess the physiological problems and self-care ability of elderly patients with schizophrenia, which also happens to be the focus of the clinical teaching program that guides students' learning.

In this study, the nursing students in the internship program said that at the beginning, they were afraid to care for the psychiatric patients because of the stigma and stereotypes surrounding psychiatric illness. They were afraid that patients would act aggressively, that their psychiatric symptoms could not be controlled or changed, and that the stress of the internship would affect their emotion and learning behavior. This pressure according to previous reports on psychiatric internships not only affects learning interest, performance and effectiveness, but also students' physical and mental health (Tsao, 2011). Research reports that the stress of working in a psychiatric nursing internship program will cause students to retreat in fear, adversely affecting future learning outcomes and reducing student satisfaction with learning(Chien, Chung, Lin, \& Tsay, 2006; Huang, Lin, Ho, Chang, \& Chen, 2015; Lin \& Huang, 2011)..

Martin \& Happell (2001) mentioned that before the internship, the students would become anxious because they were worried that the psychiatric patients would be violent and threaten their personal safety. However, the students interviewed in this study indicated that the teachers and preceptors helped them interact with the elderly schizophrenia patients to reduce the risk that patients would ignore them. Students understood that caring for elderly patients requires patience, careful observation, and understanding of their characteristics. This learning experience gradually changed the stereotype of the elderly patient with schizophrenia and as a result they learned to care for these elderly patients. The results of this study and other clinical teaching studies reflect the need to help students prepare for the internship environment. Students can be exposed to the teacher's teaching style, materials used in the internship, preceptors' teaching attitudes, etc. This can guide nursing students toward a positive understanding of nursing elderly patients at the internship stage, and shape their ability and motivation to deliver care to elderly patients(Liu, Chung, and Wu, 2004; Lin and Huang, 2011). Establishing therapeutic interpersonal relationships with patients is an important core practical ability for nurses engaged in psychiatric 
and mental health care (Huang, 2015; Shiau, Chang, Rong, Kang, 2010; Lee, 2015).

Nursing students in a psychiatric internship are still novices. The students interviewed in this study indicated that they needed clinical guidance from the clinical teachers and preceptors including demonstration of therapeutic communication skills and help with exploring the meaning of and cultivation of student nurse-patient interactions. After a few weeks of internship, students become familiar with and experience the language and vocabulary used for communication and interaction by older patients. Nursing students establish therapeutic relationships with patients under guidance, enabling patients to express their thoughts and feelings and receive care. The aim of the students' experience should be establishment of therapeutic relationships in a clinical practice and teaching setting. In addition, the increased amount of self-reflection by nursing students in learning situations, can help students to eliminate the stigma of geropsychiatric illness and convey warmth, respect, and acceptance to patients. The learning process enhances the therapeutic significance of student-patient interactions, self-confidence, and the students' positive self-evaluation of their care delivery to patients (Baglin \& Rugg, 2010; Happell et al., 2015; Hörberg et al., 2014; Lowenberg, 2003; Shiau, 2006; Yam \& Rossiter, 2000).

\section{Conclusion}

The literature on the clinical practice skills of students caring for elderly schizophrenia patients emphasizes that practice has many benefits including: improving students' skills and knowledge, reducing their fear and anxiety about mental health care, increasing their confidence and belief that they can implement clinical assessments and procedures (Happell et al., 2015; Baglin, M.R. \& Rugg, S. ,2010). This is consistent with the results of this study that "gaining confidence" associate with teachers and other important sources of clinical learning (Berhanu et.al., 2018; Happell, Gaskin, Byrne, Welch \& Gellion, 2015;Maryam et. al., 2018; Parvan, Hosseini \& Bagherian, Baglin, \& Rugg, 2018). In clinically challenging learning situations, teachers can provide demonstration and role play learning models. If nursing students observe teachers treating patients attentively and sincerely, they will become more willing to emulate this behavior. Under the teacher's guidance, nursing students can reflect on the challenges of caring for elderly schizophrenia patients. More important is that during this internship, students can adapt through observation and self-reflection (Lee, 2013; Maryam et. al., 2018; Story \& Butts,2010).

\section{Study Limitations and Recommendations}

This study explores the clinical learning experience of nursing students caring for elderly patients with schizophrenia, and not other elderly psychiatric patients. The nursing students interviewed in this study were primary learners and their learning experience was limited to their four-week psychiatric nursing internship. This study did not address the learning needs and experience of students in a setting of continuous care for elderly patients with schizophrenia. Older psychiatric patients have complex problems and the nursing competence necessary to deal with these problems can only be acquired over a much longer internship period. By proving student-centered teaching during clinical practice can satisfy the learning needs of nursing students in caring for elderly psychiatric patients. Further development of geropsychiatric nursing internship courses and teaching methods will promote the competence-based of geropsychiatric nursing of nursing students.

\section{Acknowledgments}

We express our sincere gratitude to the National Tainan Junior College of Nursing for supporting this study. We thank all of the participants for providing their time and energy to this project without which this study would not have been possible.

\section{References}

Baglin, M. R., \& Rugg, S. (2010). Student nurses' experiences of community-based practice placement learning: a qualitative exploration. Nurse Educ Pract, 10(3), 144-52. https://doi.org/10.1016/j.nepr. 2009.05. 008

Batchelor-Aselage, M., DiMeglio, B., Aaron, C., \& Dugger, B. (2014). Infusing Geropsychiatric Nursing Content Into Curricula: Challenges and Solutions. Journal of Nursing Education, (7), 387-394.

Beck, C., Buckwalter, K., \& Evans, L. (2012). Geropsychiatric nursing competency enhancements. POGOe-Portal of Geriatric Online Education. Retrieved from http://www.pogoe.org/ productid/20660

Berhanu, B. B., Berihun, A. D., Bewket, T. T., Tesfaye, D. A., Eleni, T. T., \& Workie, Z. W. (2018). Effective Clinical Teaching Behaviors Views of Nursing Students and Nurse Educators at University of Gondar, Northwest Ethiopia: Cross-Sectional Institution Based Study. Journal of Caring Sciences, 7(3), 119-123.

Chen, P. H., Shiau, S. J., Rong, J. R., \& Huang, J. Y. (2006). The Construction of Clinical Competence Criteria in the Therapeutic Nurse-Patient Relationship in Psychiatric Mental Health Nursing. The Journal of Psychiatric Mental Health Nursing, 1(1), 8-14. 
Cheng, S. T., Yip, L. C., Jim, O. T., \& Hui, A. N. (2012). Selfperception of aging and acute medical events in chronically institutionalized middle-aged and older persons with schizophrenia. Int J Geriatr Psychiatry, 27(9), 907-913. https://doi.org/10.1002/gps.2798

Chiang, C. K., \& Yang, Y. N. (2018). First Experience of Clinical Practice for Students of a 4-Year Nursing Program at a University of Technology in Central Taiwan. VGH Nursing, 35(2), 163-172.

Chien, S. H., Chung, U. L., Lin, K. C., \& Tsay, S. L. (2006). Learning Difficulties in Baccalaureate Nursing Students: A Factor Analysis. The Journal of Health Science, 8(2), 132-143.

Choi, H., Hwang, B., Kim, S., Ko, H., Kim, S., \& Kim, C. (2016). Clinical Education in psychiatric mental health nursing: Overcoming current challenges. Nurse Education Today, 39, 109-115. https://doi.org.autorpa.ntunhs.edu.tw/10.1016/j.nedt.2016.01.021

Colaizzi, P. F. (1978). Psychological research as the phenomenologist views it. In R. S. Valle, \& M. King (Eds.), Existential-phenomenological alternatives for psychology (pp. 48-71). New York, NY: Oxford University Press.

Happell, B., Gaskin, C. J., Byrne, L., Welch, A., \& Gellion, S. (2015). Clinical placements in mental health: a literature review. Issues in Mental Health Nursing, 36(1), 44-51. https://doi.org.autorpa.ntunhs.edu.tw/10.3109/01612840.2014.915899

Henderson, S., Happell, B., \& Martin, T. (2007). Impact of theory and clinical placement on undergraduate students' mental health nursing knowledge, skills, and attitudes. International Journal of Mental Health Nursing, (2), 116-125.

Hörberg, U., Carlsson, G., Holst, H., Andersson, N., Eskilsson, C., \& Ekebergh, M. (2014). Lifeworld-led learning takes place in the encounter between caring science and the lifeworld. Clinical Nursing Studies, 2(3), 107-115. https://doi.org/10.5430/cns.v2n3p107

Hsieh, C. J., Su, S. F., Liu, W. I., Kao, T. T., \& Hung, T. M. (2015). An Exploration of Nurses' Experiences in the Care of Elder Patients with Psychiatric Disorders. The Journal of Psychiatric Mental Health Nursing, (2), $1-11$.

Hsu, C. C. (2012). Handicapped premature aging and life expectancy basic research (101M7218). Taipei: Ministry of Health and Welfare.

Huang, Y. H., Lin, M. F., Ho, H. J., Chang, L. N., \& Chen, S. (2015). An Experience Applying the Teaching Strategies of Cooperative Learning and Creative Thinking in a Mental-Health Nursing Practicum for Undergraduates at a Technical College. The Journal of Nursing, 62(2), 77-83.

Hweidi, I. M., \& Al-Obeisat, S. M. (2006). Jordanian nursing students' attitudes toward the elderly. Nurse Education Today, 26, 23-30. https://doi.org/10.1016/ j. nedt. 2005. 06.003

Jeste, D. V., \& Maglione, J. E. (2013). Treating older adults with schizophrenia: challenges and opportunities. Schizophrenia Bulletin, 39(5), 966-968. https://doi.org/10.1093/schbul/sbt043

Karimollahi, M. (2012). An investigation of nursing students' experiences in an Iranian psychiatric unit. Journal $\begin{array}{lllll}\text { of Psychiatric and Mental Health } & \text { 738-745. }\end{array}$ https://doi.org.autorpa.ntunhs.edu.tw/10.1111/j.1365-2850.2011.01850.x

Ketola, J., \& Stein, J. (2013). Psychiatric clinical course strengthens the student-patient relationships of baccalaureate nursing students. Journal of Psychiatric and Mental Health Nursing, 20(1), 23-34. https://doi.org/10.1111/j.1365-2850.2012.01878.x

Kobau, R., Dilorio, C., Chapman, D., \& Delvecchio, P. (2010). Attitudes about mental illness and its treatment: validation of a generic scale for public health surveill-ance of mental illness associated stigma. Community Mental Health Journal, 46(2), 164-176. https://doi.org/10.1007/s10 597-009-9191-x

Kuven, B. M., \& Giske, T. (2019). Talking about spiritual matters: First year nursing students' experiences of an assignment on spiritual conversations. Nurse Education Today. https://doi.org.autorpa.ntunhs.edu.tw/10.1016/j.nedt.2019.01.012

Lee, J., \& Chung, U. L. (2012). Clinical Nursing Education. The Journal of Nursing, 59(5), 5-9. https://doi.org/10.6224/jn.59.5.5

Lee, Y. Y. (2015). Students graduating nursing faculty willingness to engage in employment and the expected angle of psychiatric care color pressure-in a psychiatric teaching hospital for example. Unpublished master 
dissertation. MeiHo University, Pingtung, Taiwan.

Li, S. H. (2013). An Experience of Cultivating Caring Behaviors for Nursing Students. Leadership Nursing, 14(4), 28-39.

Lin, M. F., \& Lee, Y. Y. (1995). Nursing Students' Perceptual Changes during Psychiatric Clinical Practicum. The Journal of Nursing, 42(1), 38-46. https://doi.org/10.6224/JN.42.1.38

Lin, M. Y., \& Huang, S. Y. (2011). Promoting Nursing Students' Satisfaction with the Internship Program. Leadership Nursing, 12(3), 102-112.

Liu, F., Chung, F. F., \& Wu, C. Y. (2004). The Lived Experiences of Student Nurses during First Stage Medical-Surgical Nursing Clinical Practice. Chang Gung Nursing, 15(4), 391-402.

Lowenberg, J. S. (2003). The Nurse-Client Relationship in a Stress Management Clinic. Holistic Nursing Practice, (2), 99-109.

Maddineshat, M., Hashemi, M., Besharati, R., Gholami, S., \& Ghavidel, F. (2018). The effectiveness of clinical teaching of mental health courses in nursing using clinical supervision and Kirkpatrick's model. Electronic Physician, 10(1), 6265-6272. https://doi.org/http://dx.doi.org/10.19082/6265

Martin, T., \& Happell, B. (2001). Undergraduate nursing students' views of mental health nursing in the forensic environment. Australian New Zealand Journal of Mental Health Nursing, 10(2), 116-125.

Maryam, M., Mitra, H., Reza, B., Sepideh, G., \& Fatemeh, G. (2018). The effectiveness of clinical teaching of mental health courses in nursing using clinical supervision and Kirkpatrick's model. Electronic Physician, 10(1), 6265-6272. https://doi.org/10.19082/6265

Mason, H. D. (2018). The experience of resilience among nursing students: a qualitative study. Journal for New Generation Sciences, 16(1), 62-78.

McCabe, M. P., Russo, S., Mellor, D., Davison, T. E., \& George, K. (2008). Effectiveness of a training program for carers to recognize depression among older people. International Journal of Geriatric Psychiatry, 23(12), 1290-1296. https://doi.org/10.1002/ gps.2067

Parvan, K., Hosseini, F., \& Bagherian, S. (2018). The relationship between nursing instructors' clinical teaching behaviors and nursing students' learning in Tabriz University of Medical Sciences in 2016. Education for Health, 1, 32-38.

Rafati, F., Nouhi, E., Sabzehvari, S., \& Dehghan-Nayyeri, N. (2017). Iranian Nursing Students' Experience of Stressors in Their First Clinical Experience. Journal of Professional Nursing, 33(3), 250-257.

Rong, J. R., Lin, H. R., Liu, C. Y., \& Hsu, S. C. (2013). Apply Action Learning for Fostering Nursing Students' Gerontological Caring and Service Competences: an Example of Intergenerational Service-Learning Course. (NSC 101-2511-S-227-004). Taipei: Ministry of Science and Technology.

Rong, J. R., Lin, H. R., Liu, C. Y., \& Hsu, S. C. (2014). To Evaluate Intergeneration Service-Learning Program in Promoting Nursing Students' Social Awareness, Community Service Competences, and the Ability of Elderly Interaction (NSC102-2511-S-227-004). Taipei: Ministry of Science and Technology.

Rong, J. R., Wu, C. S., \& Liao, S. J. (2018). Development of Geropsychiatric Nursing Role and Competency. Yuan-Yuan Nursing, 12(3), 5-13.

Sheu, S., Lin, H. S., \& Hwang, S. L. (2001). The Relationships among Stress, Physio-Psycho-Social Status, Coping Behaviors and Personality Traits of Nursing Students during First Time Clinical Practice. The Journal of Nursing Research, 9(3), 233-246.

Shiau, S. J., Chang, K. Y., Rong, J. R., \& Kang, Y. X. (2010). An Exploration of Therapeutic Interpersonal Relationship Essentials. Journal of Nursing and Healthcare Research, 6(2), 125-132.

Shiau, S. J., Chiang, Y. T., Huang, Y. C., Chiu, P. R., Feng, R. F., Heh, S. C., \& Chen, C. W. (2006). The Life Cultivation of Nursing Education Touched by Care, Concern and Compassion. Journal of Medical Education, 10(1), 1-7.

Story, L., \& Butts, J. B. (2010). Compelling Teaching with the Four Cs: Caring, Comedy, Creativity, and Challenging. Journal of Nursing Education, (5), 291-294.

Thomas, S., \& Bhattacharya, C. (2012). A study to assess the change in attitude and perceived stress of nursing students during their first mental health clinical placement. International Journal of Nursing Education, (1), 69-72. 
Tsao, T. Y. (2011). The Correlation of Personality Trait, Practice Stress and Coping Strategies among the Nursing Students who took Practice in Psychiatric Ward. Unpublished master dissertation. National Taipei University of Education, Taipei, Taiwan.

Van Manen, M. (2016). Researching lived experience: Human science for an action sensitive pedagogy. New York, NY: Routledge.

Wirihana, L., Welch, A., Williamson, M., Christensen, M., Bakon, S., \& Craft, J. (2018). Using Colaizzi's method of data analysis to explore the experiences of nurse academics teaching on satellite campuses. Nurse Researcher, 25, 30-34.

Yam, B. M. C., \& Rossiter, J. C. (2000). Caring in nursing: perceptions of Hong Kong nurses. Journal of Clinical Nursing, 9(2), 293-302.

\section{Copyrights}

Copyright for this article is retained by the author(s), with first publication rights granted to the journal.

This is an open-access article distributed under the terms and conditions of the Creative Commons Attribution license (http://creativecommons.org/licenses/by/4.0/). 